International Journal of Linguistics, Literature and Translation (IJLLT)

ISSN: 2617-0299 (Online); ISSN: 2708-0099 (Print)

DOI: 10.32996/ijllt

Journal Homepage: www.al-kindipublisher.com/index.php/ijllt

\title{
Role of Social Media in English Language Learning to the Adult Learners
}

Dr. Meenakshi Sharma Yadav

Assistant Professor of English, Community College for Girls, King Khalid University, Abha, Saudi Arabia.

Corresponding Author: Dr. Meenakshi Sharma Yadav, E-mail: kkudrmeenakshi@gmail.com

ARTICLE INFORMATION

Received: November 22, 2020

Accepted: January 14, 2021

Volume: 4

Issue: 1

DOI: 10.32996/ijlt.2021.4.1.25

\section{KEYWORDS}

Apps, Gamify, iSpeaker, Podcasts, iWriter, ELL, Duolingo, Edmodo,

Twitter, YouTube, Snapchat

\section{ABSTRACT}

Today social media has become part and parcel of adults' lives. Adult learners use social media much as a key to learn and improve their English as a foreign language (EFL) in academics. Currently, English instructors also encourage their adult learners within the realm of technologies. These learners are too self-motivated to use social media tools to learn English language skills. During texting, chatting, and socializing with friends, family, and global society on Facebook, WhatsApp, Blogs, Wikis, Linkedln, YouTube, Twitter, Telegram, Hangout, and Snapchat, social media are facilitating and enhancing the process for both teachers and the adult learners worldwide. Due to proliferation of advanced technological equipped electronic handy-gadgets, like smartphones, tablets, laptops, and watches, EFL learners (EFLL) with different social media applications (Apps) and tools have become easy, mobile, and flexible. Even spectacular innovation and creation of mobile Apps of international testing agencies and institutes for EFLL are available formally and informally worldwide. Therefore, in this scientific descriptive research article, the critical study investigates the hypothetical propositions about the presumed relations among observed phenomena and personal experience of various websites and social media Apps' interwoven role, creative ways of functioning, and prospects scientifically in the EFLL for adult learners. An adult learner can master a specific skill while using these Apps on social media. Moreover, it is supposed to be handled meticulously and precisely. In that case, social media can prove a boon and panacea for adult learners inside and outside the classroom.

\section{Introduction}

An adult learner is a mature student who involves her/himself in learning procedures in a specific criterion of being experienced from the teenage platform. Therefore, adult learners are higher secondary school students; however, young adult learners are tertiary or preparatory year program students at college. Here, all categorized adult learners have been included whose primary language or mother tongue is not English. Simultaneously, English is a second language and a foreign language for adult learners in this research attempt is also a criterion. ESL adult students require additional English language support to develop reading, writing, listening, and speaking skills accurately and thinking critically. These young adult learners can understand a complex text; but they have trouble with the correct uses of vocabulary, grammar, and syntax. Therefore, they are intermediate (adult- B1) and upper-intermediate (young adult- B2) level learners. These adult learners are pulled out of their general education classes for specialized and intensive English language mainstreamed into the general and specific education classes.

Various social media tools have been used for various purposes in academics and non-academic premises, which have dramatically changed the EFLL landscape in the digital and e-Learning revolutionary era. It is easy to learn English online in self-paced programs and amazingly easy to immerse the students in an English communication environment. Tools of social media such as websites, web links, and networking applications (Apps) for social networking and microblogging are all forms of electronic communications that build on the ideological and technological foundations of Web 2.0 and that allow the creation and exchange of user-generated content (Kaplan \& Heinlein, 2010, p. 61). Through electronic communication, users create online communication to share the latest information, interwoven opinions, relevant beliefs, mass ideas, personal messages, and other contents to decoding them among person to persons. All social networking sites have unique functional features. However, all of them share one common trait, which is enhancing communication among their users. All of this means that social media are no longer simply a form of amusement for younger generations (Andreas M. Kaplan, 2015). Social media is a media used through various electronic devices and rechargeable

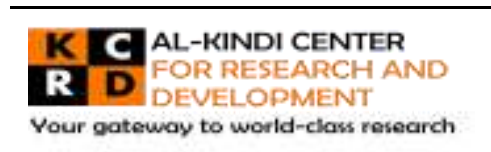

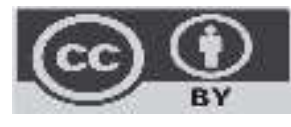

Published by Al-Kindi Center for Research and Development. Copyright (c) the author(s). This open access article is distributed under a Creative Commons Attribution (CC-BY) 4.0 license 
devices like mobile phone, the computer, tablet, other invented latest electronic gadgets and so many other ways to facilitate the people while sharing the ideas and with others easily and systematically. It is used mostly for communication and awareness around the world (Kaplan Andreas and Michael, 2010). It has not left any literates of the world untouched, creating and sharing information digitally worldwide. With the ever-growing craze for social media, most educated people have made them a part and parcel of their lives.

With the ease and affordability of smartphones and other electronic smart-gadgets installed with the latest Apps, social media has reached almost every nook and corner of the 'glocal' (global 'glo' to local 'cal' - all dialects and vernaculars of each corner of the world). Social media has influenced and affected every fact and phase of all categorized generations' lives, including our communication. With the advent of world-class technology of $4 \mathrm{G}$ (emerging $+\mathrm{G}$ ) and the internet of things (loT), there is a broad scope of social media in the education industry. YouTube, Facebook, WhatsApp, Twitter, and the new emerging latest social tools can be a catalyst and a new channel for achieving the ESL education realm's growth goals.

\section{Methodology}

The present critical study is a systematic, objective analysis and recording of controlled observation that leads to the development of generalizations, principles, and resulting in the predictions of events based on descriptive and evaluative research methodology. The deductive reasoning, personal experience, mass-opinion, and scientific inquiry in this research explore the descriptive correlational, explanatory, and exploratory objectives to acquire the new knowledge and updated information with step-to-step social media role in EFLL for the adult learners.

\section{Literature Review}

The theoretical framework of this riveting, novel, ethical, and relevant research article is a natural extension of the literature review, the purpose of which, amongst other things, is to highlight gaps and shortcomings with the existing working in its perspective research field that needs to be fixed to address and make sense of EFLL with social media sources, Apps, and forms in the digital education milieus. Social media is a set of websites, web links, intranets, Apps, and any net-based links, for instance, Facebook, WhatsApp, Twitter, Instagram, Messenger, Skype, and many more Apps related of online English teaching-learning, like British Council, iWrtier, iSpeaker, EDMODO, DUALINGO, Podcasts which have been continuously becoming the most visited websites and Apps on the worldwide college campuses since their creation. Due to this proliferation of these social sites in advent popularity, the subject of social networking has grown widespread as an idea and concern for both ESL instructors and adult learners. Adult learners can get any keen information and desirable knowledge in a click on social media. At Lee University, it has been observed that a growing number of instructors have indeed created Facebook profiles, according to Pascarella and Terrenzini (1991). Some of the most effective influential faculty members are those that create an informal relationship with their students. Over recent decades, numerous studies have suggested that student and faculty interaction have a notable impact on students' outcomes in the intellectual and the social realm.

Moreover, the millennial generations of students are digital natives coming to higher education with extensive social media experience. Businesses and other organizations are expecting their recruits to have high proficiency in these technologies, too. The movement to richer media such as videos, blogs (vlogs) is assessed. Caveats for implementing the social media in higher educational settings are noted (Robbins Ball, S., 2008). And also in 2007, a survey conducted by marketing firms, like Noel -Levitz and James Tower, and the National Research Center for College and University Admissions (NRCCUA) found that students expressed a preference for electronic communication and greater interest in using social networking to interact with colleges and make enrollment decisions as compared to their white counterparts (Livingstone, D.W. , 2000).

Consequently, colleges and universities are beginning to embrace social media and realizing the potential power and implications for using it as a component of their overall marketing mix today. This guide will introduce us to some of the more popular social media forms, including Facebook, MySpace, YouTube, Flickr, Twitter, blogs, and del.icio.us. One hundred forty-eight colleges and universities responded to a survey in July 2008 answering what social media they were using most, how they were using it to reach their target audiences, and which department(s) at the college was responsible for maintaining it. This guide will review existing literature available in this subject area, identify implications for and against using social media and discuss best practices, recommendations, and considerations for higher education marketers (Junco, R. \& Cole -Avent, G.A. 2008). Further ahead, students can be benefitted from online tutorials and resources that are shared through social networks and LMS's. Social media enables users to share their views with others and make social relationships with others and make social relations with other users (Pilli, Olga, 2014). C. Tantarangsee, N. K., \& A. S. (2017) highlighted that online blogs like social media are broadly supported by a constructive approach, as they underscore learners' interaction. The importance of social media full of interaction English learning process is necessary and quite helpful in the target language that facilitates ESLLs. And, a systematic amalgamation of language courses on reading and writing skills, social media has a great pedagogical potential for improving language awareness, grammar, vocabulary, and fluency (Wu \& Wu, 2011), development language competence (Dahdal, S. 2020) are offering learning opportunities for language skill practice (Thorne, S.L. 2010), therefore, recent studies discovered that well-established social media Apps usage 
facilitated ESLLs to interact with others languages (Thorne, 2010; Wu \& Wu, 2011), and positive prospective towards ESLL (Thorne, 2010; Tubagus, 2019). Therefore, this literature review presents a close-clear picture of social media in which adult learners of ESL show their keen interest to improve and enhance English language skills intentionally and purposefully.

Therefore, the further study sets off through reviewing above mentioned limited exposures and references that promote the aims of the research to investigate and explore the present challenged and emerging problems in this research field and their solutions. This article is not to affect the nature and commercial image of any Apps, web links, and social media at any conditions and terms.

\section{Pedagogical Principles of EL Skills through the Social Media}

Social media facilitates communication by sharing the latest information, documents, photos, videos, new ideas, thoughts, interests, opinions, and suggestions among the virtual communities and networks. Therefore, a user of social media can share with anyone on the Earth instantaneously. It is globally being thought that more than two-thirds of adult learners are social media users. The most popular social media websites are- Facebook, YouTube, WhatsApp, Twitter, Instagram, Facebook Messenger, WeChat, QQ, Sino Weibo, Douyin/TikTok, Likee, Linkedln, Skype, QZone, and many newer emerging Apps in everyday world.

Social media's usability challenges the traditional models and keeps away hierarchical tools and elements associated with the longstanding way of teaching and learning English Language (EL) skills. The social media window is like an active, communicative, open, transparent, and vocal window to all learners equally. Hence, it may allow learners to communicate, collaborate, and encourage remote learning and enhance EL skill programs. It has also been observed recently that eight out of ten adult students search terms, items, and contents on social media, web links, or Apps frequently. Learners should also go to catch and collect the new and latest information and entertain them with other learners passionately. Even adult learners can collect accurate data, valid data through the Google Survey Monkey and Facebook Polls, to their stakeholders' ESL attempts. Adult learners can create Google Classroom, Google Meet, Google Blogger, G Suite for Education, blogs, and ePortfolio where they can write a piece of writing or any comment-contents that can be rewritten, edited, and elaborated later if they need to get corrections and add something more. Learners can also download ESL based tasks and quizzes- photos and images from Flickr and Pinterest, and can make a presentation on the Slides-share.

On the other hand, social media is an ever-changing and ever-evolving web-based platform which usability, tools, tactics, and strategies are being changed less or more and new emergences anytime. However, due to the adult users' inherent intelligence, social media functions can be enhanced conveniently and comfortably. This electronic and digital teaching pedagogy is highly successful and fully resultant to the digital world's remote learners.

\section{Role of Social Media in EL Skills}

Social media plays a vital role in getting learned EL skills because it provides possible and featuring opportunities to adult learners to improve their listening, speaking, reading, writing skills, and more similarly. Learners read the new text and learn new phrases on social media to enhance their communicative vocabulary. Social media use amongst adult learners has increased compared to books and other text materials while getting information related to the EL. Now the adult learners may use different sources and tools on social media to improve their vocabulary and speech. To improve their speaking skills, adult learners can make their own Facebook groups of English language learners (ELLs) to talk and chat frequently and candidly. They can follow or join some organizations, companies, and teachers who share language learning platforms and pages. YouTube can be used to improve for all EL skills like pronunciation, listening, speaking, writing, grammar, syntax so on. Some of the Apps that may develop listening skills productively are BBC news/radio, YouTube, Podcasts, Audiobooks. The improvement of speaking skills may include Hello English, iSpeaker of OALD, Podcasts by the British Council. Developing the reading skills may have Speed Reading, Readerly, Flipboard, Play Newsstand, and BBC News; writing skills development may include iWriter of OALD, English writing skills, and Blogging. Except from them, there are also various Apps of IELTS, TOEFL, JRE, OET, CAE, CPE, PTE, and other international English language testing institutes and agencies online, which are equally helpful tools to enhance all the intensive EL skills programs together fruitfully to adult learners. The mobile Apps help to develop an adult learner's EL listening, speaking, reading, writing, and critical thinking like spelling, vocabulary, grammar, pronunciation, idioms and phrases, sentence framing, and writing of paragraph, essay, article, report, and literary skills which are listed based on their usability and availability.

Edmodo is a useful software for the incorporation of social media in language teaching to adult learners. Other Apps, for example, Duolingo that gamifies ELL skills, which makes it a fun activity for the learners productively.

Despite that, viewing the craze for social media, we may be hopeful that it will make ELL and ELT easier and more enjoyable. Adult learners can easily be connected to native speakers to interact and improve their accurate English accents and pronunciations. In short, the teaching and learning practice and enhancement through social media is a kind of distance learning process that occurs when teachers and students move a normally in-person class to a provisional online interplanetary. Therefore, distance learning is also a kind of e-Learning that includes online, flipped, blended, virtual, and visual electronic learning. Still, it is not a kind of online learning entirely because it is not learning designed for purely digital spaces, whereas elearning is. 


\section{Types of Social Media}

Social media can broadly be divided into the following related and overlapping categories:

1. Instant Messengers: WhatsApp, Facebook, Messenger, Skype, Google Meet, Zoom, IMO, Tango,

2. Social Networking Sites: Facebook, Linkedln,

3. Social News: Flipboard, Play Newsstand, BBC News, CNN, HT, TOI, DNA,

4. Media Sharing: YouTube, Instagram, Flicker, Intranet,

5. Wikis: Wikipedia, Emojipedia, online dictionaries,

6. Blogging: WordPress, Google Blogger, Blogspot.com,

7. Micro Blogging: Twitter, Telegram,

8. Emailing: Gmail, Outlook, Yahoo, Hot mails,

9. Apps of Podcasts by British Council, Audiobooks, Hello English, iSpeaker and iWriter of OALD, Speed Reading, Readerly, Hipboard, Cambly, Duolingo, Netflix, and other Apps of IELTS, TOEFL, JRE, OET, CAE, CPE, PTE and so on the other English enhance learning programs for the learners by many online international EL testing institutes and agencies.

Some Apps are synchronous on social media, like Instant Messengers, Social Networking Sites, Microblogging, and some are asynchronous, like Emailing, Blogging, Media Showing, Social News, and Google News. The above subdivision is as following in two categories-

Synchronous Communication Tools: These tools enable the users to communicate and collaborate in real-line in the 'same timedifferent place' mode. Users get a spontaneous reaction and immediate feedback through them, e.g., Instant Messengers, Social Networking Sites, and Microblogging. They are mostly used for chatting, and audio-video conferencing.

Asynchronous Communication Tools: This facilitates the ESL adult learners to interconnect and collaborate over time through a 'different time-different place' mode. This is widespread tractability with asynchronous ESL enhancement, which arises in two formulae; facilitated and self-paced peers.

\section{Apps and Web Sites for EL Skills}

In the present time, where to be upgraded with the current worldwide issues and local social emerging elements, EL skills is to be learned by everyone for better personal and professional life. However, nowadays, in remote areas where the professional EL teachers' availability is an original problem; hence, social media Apps may prove to be a boon for adult learners. Social media use offers learners the opportunity to adult learners who can learn correct pronunciation-pitch, intonation, rhythm, accurately assess their fluency, reading texts, writing comments, blogs, reports, and the correct use of syntax. Consequently, social media's systematic and scheduled use also opens up the doors for comparison between native and non-native speech, dialectical distinction, and socio-pragmatic variation. However, hundreds of unique tools and Apps for EL learners as their second language that help the learners to master the EL and increase their EL skills purposefully. While there is no existing confirmation yet to draw practical results by means of Apps; but these Apps and web links can be chosen based on their usability and availability which are not intended to promote any Apps and web links' development agencies. These Apps and web links may be used to develop EL skills, are given below:

\subsection{Hello English}

Hello English is one of the best Apps to develop English speaking skills. Here regional languages are also available in this App as a medium of their instructions. The App provides graded steps to learn and practice speaking in the target EL. This App even checks the accuracy of the learners' spoken words with a microphone of the smartphone. The educator may create a community of adult learners and check their progress from time to time.

\subsection{OALD iSpeaker}

iSpeaker is a built-in program in the Oxford Advanced Learner's Dictionary. It is convenient in giving the practice of English speaking. The program has included videos of pronunciations for all the 44 speech sounds with examples and occasional conversations. The educator can use the videos of the program to train adult learners easily. The young learners may listen to the sounds, practice them, record them, and send them to the teacher for quality assessment. The iSpeaker App has recently been added to OALD. It often adds new words and meanings to the Oxford Advanced Learner's Dictionary. The adult learners can read about some of the most recently added words and meanings in the blog posted on The Language of Coronavirus. Examples of a few words and meanings added in May 2020 are community Spread (noun)', community transmission (noun), contact tracing (noun) corona (noun) sense 2, coronavirus (noun), covid-19 (noun), covidiod (noun), deep-clean (verb), elbow-bump (noun), elbump (noun) flatten the curve (idiom), hand-gel (noun), hand-sanitizer (noun), health- professional (noun), herd-immunity (noun), hot zone (noun), nCoV (noun), panic buying (noun), patient zero (noun), personal protective equipment, PPEs (noun), selfisolate (verb), self-isolation (noun), self-quarantine (noun/verb), shelter in place (idiom), social distance (noun), social distancing (noun), wet market (noun), WFH (abbreviation), work from home (idiom). 
Furthermore, the 10th edition of OALD comes with interactive online support through the Oxford Learner's Dictionaries website and the OALD10e App. The website includes advanced features such as audio/video tutorials, video walkthroughs, self-study activities, and enhanced iWriter and iSpeaker tools - making the dictionary a must have for students, learners, and educators. Oxford University Press (OUP) statement stated that other features of the new dictionary include:

a. Oxford Speaking Tutor and online iSpeaker with pronunciation videos prepare adult examinees for their speaking examinations like British Council English proficiency exams, Cambridge IELTS, TOEIC, TOEFL.

b. There are available the real voice audios of words and example sentences in both British and American English accents for the adult learners.

c. OALD10e focuses on the language changes and assessments through the years, making sure that the language and examples used for adult learners in the new edition are relevant and up-to-date timely.

\subsection{Podcasts (British Council)}

Podcasts are episodic series of spoken word digital audio files (like audiocassettes in the previous years) of interviews, particular topics, and scientific series talks/discussions that learners can download to their electronic devices for the preferred listening. If an adult learner has a smartphone with internet access, $s /$ he can enjoy podcasts to utilize free time while either $\mathrm{s} / \mathrm{he}$ is commuting or working or relaxing. Advanced learners can create a podcast channel like a YouTube channel account where relevant podcasts can be posted to their followers. Google, English language testing agencies \& institutions, BBC, and other news channels' tailored pod, podcast, and vodcast contents are on the move to the wide ranges of the programs and highpoints which are easy to access as podcasts for a learner to download for free. By making little efforts, young learners can quickly improve their listening skills and proficiency through EL podcasts. British Council EL podcasts are available on the appropriate model to learn English promptly, which often has transcripts. Consequently, adult learners can listen and read simultaneously or look at a transcript if one part of a podcast confuses them.

Moreover, its App has lots of podcasts, short audio scripts with written literature that are as follow- The English We Speak, Podcasts in English (www.podcastsinenglish.com), Elementary Podcasts, Splendid Speaking, Better at English, Voice of America Learning English, Business English Pod, Culips ESL Podcast, ESL Pod, Luke's English Podcast, and many more.

\subsection{Netflix: Provides an Easy Platform to Enhance EL}

Nowadays, Netflix is a popular streaming service that offers a vast catalog of movies and other exciting TV shows to watch. This service is available through streaming devices as, on a smart TV, smartphones, and other intelligent electronic gadgets all-time. The only thing needed is Netflix account and internet accessibility in the electronic gadget to learn English with Netflix's help. Here, an adult learner can find a lot of EL programs. Hence, learners can a broad scope to find programs that fit their current understanding level. This platform is more comfortable to learn ESL if adult learners pick subjects or stories which interest them.

Moreover, learners can watch the series or movies with English subtitles which help them understand what they are hearing and enhance their listening-speaking skills. If the students are beginning their English learning, they can select programs with less complicated language. Along with it, they are exposed to a wide variety of accents and intonation drills. Regardless of whether they are learning the UK or American English, they will be exposed to several different accents. Exposure to the various accents dramatically adds to their ability to understand the language.

Further, students are exposed to a broader vocabulary and conversational English in formal, informal, regional speech, and many slang. The more, learners hear a word spoken, the easier it becomes to say the word correctly and improve their pronunciation accurately.

\subsection{Emoji in EL}

Emoji are frequently used on social media nowadays. Emoji, from the Japanese 'e' that means "picture" and 'Moji' that means "character", is a recent invention of joker symbols. These are pictographs of faces, glued-puffy objects and symbols, yellow cartoony faces with various belonging expressions and gestures of families, buildings, animals, food objects, mathematical symbols, and many more, which are specified in Emojipedia. These graphics are facilitated in the different Apps while using social media to enhance EL symbols for vocabulary, colloquial concepts, expressions, message responses, and objects' understandings. EL vocabulary is related to empathy; the Emoji is related to understand other people's feelings and emotions, and to express their own. There are many symbols, cues, and non-verbal communication signs acknowledged by the learners, and then they can apply them in writing a text, paragraph, and a message. These Emoji cues and symbols are very easy to use and effective to learn many different categorized vocabularies.

\subsection{DUOLINGO}

It is a fantastic and fascinating tool, available as both an App and a website, making learning languages fun by offering highly visual and interactive tutorials for adult learners. It trains them in their grammar, spelling, and even valid pronunciation. The 
learning process is carried away into different levels, and the learners earn crisis for every level completed successfully. Therefore, taking a lesson is like playing a computer game. For every wrong answer, the learner loses a life. Each question has a discussion attached to it, where experts from the DUOLINGO team help the adult learners out with any difficulty which s/he has. It mostly works on the translation method to teach the target language. This software also provides some of the popular types of questions including translation sentences between languages, filling in the blanks, choosing the correct option. There are even oral translations and spoken translation to the second mother tongue learners. Some questions are pictorial to keep things interesting. The learner can add friends and check their progress versus their friend's progress.

\subsection{EDMODO}

This software and App need special mention, as it is one of the best social media Apps for educational purposes. It allows educators to create a local group/ community of students and help them learn together. Hence, a student can share tasks, quizzes, ideas, opinions, articles, and multiple academic contents with the students. The tasks done and submitted by the students are also evaluated through the software. It is also convenient in creating surveys. More and more educational tools are added in this software's updates, making it even more useful.

\subsection{CAMBLY}

Cambly is a digital social networking platform that allocates students from all over the world to connect with native English tutors for complete courses like conversations, structured English lessons, different exam preparations, business English, job interview preparations, and everyday English conversations. Cambly App gives the adult learners instant access to native English speakers over live video chats. Tutors help the learners $24 / 7$ whenever students have time to do their practice the EL skill courses. The friendly English tutors are ready to help the learners' practice conversation skills, pronunciation, and other EL skills they like to improve. The adult learners can browse the tutors' profiles to find tutors with relevant highly influencial and extensive experience or interests. The tutors have a wide range of education and professions. The adult learners can also browse the Cambly App on their smart mobiles or a computer with a web camera.

\subsection{Mobile Messenger Apps}

Using a mobile messenger App, such as WhatsApp, Facebook Messenger, Snapchat, Telegram, and Twitter support English's remote learning, is instrumental when learners can only use the internet on their mobile phones. There are a variety of ways that these Apps can be used. These mobile messenger Apps can be used formally and informally for ELL. Here an adult learner can be a member of one group who set up for the whole class, which is broadcast-only; this means that the group administrator can send them messages. This group should be utilized to share essential and new information with the whole class, or the students can also create separate groups within the category, perhaps up to ten students in each one. This is helpful to make the conversation more comfortable to manage. Through these social media tools, the teacher can send a short video to say hello to the learners and tell them the plan for the preferred day or the prescribed time. While the teacher texts the students and the students reply through a text, it is easy to enhance the vocabulary, and the students can learn a lot of new vocabulary items. Teachers and students can share photos of objects or drawings to explain the words. Students can record themselves saying the words and send the audio file. It is an elementary medium to share poems as text or audio files for listening. Introducing new vocabulary and sending some questions to the learners is an excellent way to learn $\mathrm{EL}$, as such attempts have been succeded awesome during the COVID19 pandemic, too.

\subsection{WhatsApp}

WhatsApp can be used to send exciting information / questions on the topics beyond the texts. Through this medium, many tasks can be delivered based on the textbook. A daily task or challenge can keep young learners practicing their EL skills regularly. E.g., picking up sentences from the text and making the adult learners correct the mistakes that are done deliberately by the teacher. The teacher can gamify these by giving deadlines and awarding the grades. Students need to be very clear about precisely what language skills they are learning or practicing with each task. Students can do text-only quizzes asking the learners to answer questions, match definitions or halves of sentences, or complete gaps in a short text. Moreover, this social media helps the learners to use their environment to learn EL.

WhatsApp can distract the students. The temptation to chat with friends may override its use for educational purposes. Students need to be more aware of this, and parents and teachers have to help students make effective use of smartphones towards their innovative learning methods.

\subsection{Facebook}

Facebook (Fb) is a widely used social media platform among the mass, categorized groups, and personal pages. In places where teachers and their learners may not have access to advanced digital tools or infrastructure for learning, Facebook is a quick and readily available platform for the learners. Adult learners, who have their $\mathrm{Fb}$ accounts, are ready to access the learner's need to create a mass-group to ESL lessons. To provide information, explain concepts, or set tasks, the learners can use Facebook Live's 
features. If the learners cannot be present for the live session, they can watch the recordings later. With uploaded lessons, the learners can enhance their listening skills with recorded stories, listening texts, videos explaining concepts or pronunciation, and can do tasks based on these individual themes. Learners can improve their reading skills with the text posted for them and the links shared of other reading texts, sources and with the help of some practice tasks, activities, and quizzes recorded audio files. There are some online clubs on Fb, e.g., English club for students, BBC Learning English, English Learning Club, Teaching English British Council, BBC Learning English, Daily English learning, online English testing institutes' study materials, and many more academic groups which are some of the user groups on $\mathrm{Fb}$ and being the part of these groups, a learner can learn different relevant contents and phrases on the single platform.

\subsection{Zoom}

Zoom should be facilitated as a platform for EL teaching and learning process. Using Zoom has become very famous and easy to use for beginners to advanced learners at the nook and corner of the world to teach remotely and online. Zoom has many innovative features that can help the teachers and the learners deliver and receive online EL lessons. The students placed in the remote area can use the chat feature, use video, share the screen, and record the delivered lectures. The teacher can also interpret the screen that is added to the text while sharing the whiteboard feature.

Thus, Zoom allows the teachers to present a lot of contents in various ways. For example, teachers can prepare their lessons, use an e-book, share their screen with the student(s), and set homework using a screencast. Zoom's HD video and high-quality audio mean that teachers may integrate all four skills into their lessons. Students can also use the chat box features to practice their writing skills. In group classes, the teacher can create breakout rooms to set up a small group discussion, equivalent to putting a student with a partner(s) in the online Zoom class.

\subsection{Educational Websites}

Some educational websites are readily available by which adult learners can improve and develop their EL reading skills correctly. These websites provide videos featuring celebrated personalities, which create interest in the learners who wish to watch and hear their favorite figures repeatedly that, make them efficient and near the English language's upgraded level. Learners also find a treasure trove of resources, lesson plans, activities, interactive games, web tools, and a wide variety of other reading materials covering different literacy areas including reading, writing, listening, and speaking to enhance their phonemic awareness, language fluency, vocabulary, and reading comprehension skills. Additionally, adult learners can find reading materials for all levels, from beginners to advanced readers. Some web games provide a wide variety of reading materials and tips covering all EL reading skillsRead Write Think, Reading Rockets, Reading Bear, Reading Eggs, Storyline Online, and many more.

\subsection{Other Software and Video Conferencing Apps}

Some other software and Apps are also on the free of cost accessibility to ESL adult learners. As some are related to languages translating by which mother tongue is translated into English or other preferred languages. For example, Google Translate is such an App and website service that promptly translates words, phrases, sentences, and paragraphs together and other web pages between English and over 100 other languages so far. Sometimes, such translations are not accurate; but it can be taken as the support to understand its concept and context. Therefore, if ESLLs find any challenging texts to write a piece of writing in the English language, they can use Google Translate to write or translate their mother tongue into English. Furthermore, there are various web links, videos, kids cartoon, movies, and English study groups of the English skill courses on Google, YouTube, and Facebook at free of cost accessibility to improve and to learn the EL skills, e.g., English Study Here, Essential English Words, English Vocabulary Words, 7esl.com, and many more of the EL skill online courses like- IELTS, TOFEL, TOFIC, JRE, PTE, CPE so on.

Furthermore, there are some more web Apps which are used on the priority worldwide at present - Snapchat, Kahoot, Skype, Google Meet, BlueJeans, BigBlueButton, Google Hangouts, AnyMeeting (Freebinar), Webex, GoToMeeting, Sococo, Microsoft Teams, YouTube Streaming, Whereby, Yotribe, Discord, Miro, Twitch, Vimeo, Facebook Live, Wowza Streaming Engine, Hopin, and many more that are growing in the existing day-to-day. Therefore, it has become easy to learn EL skill courses for adult learners of the second and other languages at all cost and condition from global to local corners worldwide. Thus, these Apps may prove a boon and blessing to get the EL adult learners to enhance and teach easy and far better in the recent digital EL education groundbreaking.

\section{Successful Implementation}

Though social media Apps are beneficial tools, yet it can be distracting to adult learners. Due to the COVID19 pandemic, academic institutions and organizations have been physically inactive from March 2020 for about one year. During this, these tools have been using massively so it is needed to be used cautiously and carefully. The temptation to chat with friends may override its use for educational purposes. Students need to be aware of this, and parents and teachers must help adult learners make effective use of smartphones for innovative learning methods. 
While incorporating social media in EL skill teaching-learning processes, the system should be extremely vigilant and careful. Parents of the learners should also be involved in the process. The different forms of language used to communicate in social media among students, their people, and educators need to be carefully monitored; otherwise, some misunderstandings may interfere with the learning-teaching process (Rambe, 2011).

There are more than hundreds of social media Apps used by young learners for various purposes, including ELL. However, till now, they have not been tried and tested at large in the teaching-learning process. However, initially, teaching via social media should be made compulsory or not; that's been not adopted in the pedagogy yet. Necessary freedom should be granted to the educators to consider the best for adult learners of the English language skills because something that works well for a group of learners may not be that same for the other groups.

\section{Conclusion}

This research highlights critically that how do social media play a role in the ELL for adult learners through the practices and technology tools of Web 2.0 which are changed to meet the needs of ELL current time. This type of ESLL via social media to adult learners is more advanced and progressive than conventional pedagogy. Technology like tablets, PCs, Apps, and access to broadband internet are lubricating the shift to mobile ESL learning.

While learning English through social media, the communities of each learner's native context can fully be understood. Here, in these local and digital communities, a 'need to know' is born. Therefore, the 21st century has been hijacked by digital devices, and especially the adult students are held captive by many smart digital gadgets and tools. Their range of knowledge in using these digital tools is mind blowing. It may be an early prediction that incorporating social media into the education system will prove an effective and efficient ESLL task. The system, the educators, the parents, and the learners need to develop social media as an effective tool for ELL. While ELL via social media may not be an alternative to college, at least not yet, it seems to be taking steps towards the end of another system just as counter-productive as regular classes. Social media effectively replaces the concept of having a full-time tutor or attending extra classes after college.

In the future, social media is going to be more popular than ever; videos will be an exciting way forward for ELL; leading universities will offer MOOC (Massive Open Online Courses) in languages, and electronic handy smart gadgets will play a significant role in ELL.

Let it be hopeful that social media's active incorporation will immensely prove to be a useful ESLL tool to adult learners in the days to come. We can wait and watch it to gain popularity in the digital ESLL education revolution.

\section{Future Research Direction}

Learning, as well as teaching through social media, has a very cosmic field to be studied. Its global importance has not been negligible during the pandemic of COVID -19, due to which all learning were conducted through social media, Apps, and websites available for all. In the future, this research may investigate the impact of social networks on the young adult student's learning experience based on a survey involving students and teachers. The research objectives would be to explain the young adult student's learning experience when they are a part of a social network community. With the help of the questionnaires filled up by both adult learners and instructors, the study would aim to understand social networks' perception and analyze their role and utility in ESLL.

\section{References}

[1] Andreas M. Kaplan (2015). Social Media, the Digital Revolution, and the Business of Media. International Journal on Media Management, 17(4), pp 197-199. https://doi.org/10.1080/14241277.2015.1120014

[2] Akçayır, G. (2017). Why Do Faculty Members Use or Not Use Social Networking Sites for Education? Computers in Human Behavior, 71, 378-385.

[3] Ansari, J.A.N., Khan, N.A. (2020). Exploring the Role of Social Media in Collaborative Learning the New Domain of Learning. Smart Learn. Environ. 7(9). https://doi.org/10.1186/s40561-020-00118-7

[4] Al-Jarrah, T. M., Al-Jarrah, J. M., Talafhah, R. H., \& Mansor, N. (2019). The Role of Social Media in Development of English Language Writing Skill at School Level. International Journal of Academic Research in Progressive Education and Development, 8(1), 87-99.

[5] Bosch, T. E. (2009). Using Online Social Networking for Teaching and Learning: Facebook use at the University of Cape Town. Communication, 35(2), 185-200.

[6] C. Tantarangsee, N. K., \& A. S. (2017). The Use of Social Media in Teaching and Learning: A Case of SSRU"s Faculty Members. International Journal of Innovation, Management and Technology, 8(6), 471- 476.

[7] Cabrera, Lino (2018). Impact of Social Media in English Language Learning: Utilizing S. W. O.T. Analysis. Lino S. Cabrera Teacher I Palawan National School Schools Division of Puerto Princesa, pp 1-33.

[8] Dahdal, S. (2020). Using the WhatsApp Social Media Application for Active Learning. Journal of Educational Technology Systems, 49(2), pp 239-249. https://doi.org/10.1177/0047239520928307

[9] Dalton, J. (2009). Teaching and Learning through Social Networks. Retrieved

https://www.academia.edu/2612052/Social_Media_for_Language_Teaching_and_Learning 
[10] Junco, R., \& Cole-Avent, G. A. (2008). An Introduction to Technologies Commonly Used by College Students. New Directions for Student Services (124),3-17.

[11] Kaplan, A. M., \& Haenlein, M. (2010). Users of the world, unite! The challenges and opportunities of social media. Business Horizons, 53(1), 59-68.

[12] Livingstone, D.W. (2000). Exploring the Icebergs of Adult Learning: Findings of the First Canadian Survey of Informal Learning Practices. Retrieved dated 31/01/2012 from https://tspace.library.utoronto.ca/bitstream/1807/2724/2/10exploring.pdf

[13] Quadri, N., Muhammed, A., Sanober, S., Qureshi, M., \& Shah, A. (2017). Barriers Effecting Successful Implementation of E-Learning in Saudi Arabian Universities. International Journal Of Emerging Technologies In Learning (IJET), 12(06), pp. 94-107.

[14] Oxford University Press ELT (2014). Using a Social Media Project as a Tool for Motivating Young Adults Learning English. 17 June 2014 by Oxford University Press ELT.

[15] Pascarella, E. T., \& Terenzini, P. T. (1991). How College Affects Students: Findings and Insights from Twenty Years of Research. Book. San Francisco, CA: Jossey-Bass

[16] Pilli, Olga (2014). LMS Vs. SNS: Can Social Networking Sites Act as a Learning Management Systems? American International Journal of Contemporary Research, 4(5),90-97.

[17] Reyes, M. R., Brackett, M. A., Rivers, S. E., White, M., \& Salovey, P. (2012). Classroom Emotional Climate, Student Engagement, and Academic Achievement. Journal of Educational Psychology, 104(3), pp 700-712.

[18] Rambe, P. (2011). Exploring the Impacts of Social Networking Sites on Academic Relations in the University. Journal of Information Technology Education: Research. 10, 271-293.

[19] Richardson, J., \& Lenarcic, J. (2008). Text Messaging as a Catalyst for Mobile Student Administration: The "Trigger" Experience. International Journal of Emerging Technologies \& Society, 6(2), 40-155.

[20] Robbins. Ball, S. (2008). Higher Education as Virtual Conversation. EDUCAUSE Review,43(5),24-34. Retrive athttps://er.educause.edu/articles/2008/9/higher-education-as-virtual-conversation

[21] Roblyer, M. D., McDaniel, M., Webb, M., Herman, J., \& Witty, J. V. (2010). Findings on Facebook in Higher Education: A Comparison of College Faculty and Student Uses and Perceptions of Social Networking Sites. The Internet and Higher Education, 13(3), pp 134-140.

[22] Rock, M. L., \& Thead, B. K. (2007). The Effects of Fading a Strategic Self-monitoring Intervention on Students' Academic Engagement, Accuracy, and Productivity. Journal of Behavioral Education, 16(4), pp 389-412.

[23] Rodriguez, J. E. (2011). Social Media Use in Higher Education: Key Areas to Consider for Educators. MERLOT Journal of Online Learning and Teaching, 7(4), pp 539-550.

[24] Rutherford, C. (2010). Using Online Social Media to Support Preservice Student Engagement. MERLOT Journal of Online Learning and Teaching, 6(4), pp 703-711 Retrieved from http://jolt.merlot.org/vol6no4/rutherford_1210.pdf

[25] Selwyn, N. (2012). Making Sense of Young People, Education and Digital Technology: The Role of Sociological Theory. Oxford Review of Education, 38(1), pp 81-96.

[26] Sharma, Vipin (2019). Saudi Students' Perspective on Social Media Usage to Promote EFL Learning. International Journal of Linguistics, Literature and Translation, 2(1), 128-138.

[27] Shih, Y. E. (2007). Setting the New Standard with Mobile Computing in Online Learning. The International Review of Research in Open and Distributed Learning, 8(2), pp 1-16.

[28] Slim, Hadoussa \& Hafedh, Menif (2019). Social Media Impact on Language Learning for Specific Purposes: a Study in English for Business Administration. Teaching English with Technology, 19(1), pp 56-71.

[29] Thorne, S. (2010). The 'Intercultural Turn' and Language Learning in the Crucible of New Media. In S. Guth, \& F. Helm (Eds.), Telecollaboration 2.0 for Language and Intercultural Learning (pp. 139 - 164). P.I.E. - Peter Lang.

[30] Tubagus Zam Zam Al Arif (2019). The Use of Social Media for English Language Learning: An Exploratory Study of EFL University Students. METATHESIS: Journal of English Language Literature and Teaching, 3(2), 224-233.

[31] Voorn, R. J., \& Kommers, P. A. (2013). Social Media and Higher Education: Introversion and Collaborative Learning from the Student's Perspective. International Journal of Social Media and Interactive Learning Environments, 1(1), pp 59-73.

[32] Wankel, C. (2009). Management Education Using Social Media. Organization Management Journal, 6(4), pp 251-262.

[33] Williams, M. D., Rana, N. P., \& Dwivedi, Y. K. (2015). The Unified Theory of Acceptance and Use of Technology (UTAUT): A Literature Review. Journal of Enterprise Information Management, 28(3), pp 443-488.

[34] Wu, H. -J., Wu, P. -L. (2011). Learners' Perceptions on the Use of Blogs for EFL Learning. US - China Education Review, A3, pp 323-330.

[35] Yadav, M.K. (2014). Role of Mother Tongue in Second Language Learning. International Journal of Research, 1 (11), pp 572-582.

[36] Yang Jin, Schneller, Chripa, \& Roche, Stephen (2015). The Role of Higher Education in Promoting Lifelong Learning. Book, ISBN: 978-92-8201194-2

[37] Yeo, Clair M., (2015). Supplementing ESL Classroom Activities with Social Media for Young Adult Learners. Master's Projects and Capstones. 284. https://repository.usfca.edu/capstone/284.

[38] Zhu, C. (2012). Student Satisfaction, Performance, and Knowledge Construction in Online Collaborative Learning. Journal of Educational Technology \& Society, 15(1), pp 127-136. 